\title{
Design of a Teacher Education Model that Improves Teacher Educator Efficiency in Processing Teacher Candidate Data
}

\author{
By Kevin Ng \\ B.S Electrical Engineering and Computer Science \\ Massachusetts Institute of Technology, 2017 \\ Submitted to the \\ Department of Electrical Engineering and Computer Science \\ In Partial Fulfilment of the Requirements for the Degree of \\ Master of Engineering in Electrical Engineering and Computer Science \\ at the \\ Massachusetts Institute of Technology
}

June 2018

(C) Massachusetts Institute of Technology 2018. All rights reserved.

The author hereby grants to M.I.T. permission to reproduce and to distribute publicly paper and electronic copies of this thesis document in whole and in part in any medium now known or hereafter created.

Author:

Department of Electrical Engineering and Computer Science

May 25, 2018

Certified by:

Justin Reich, Director of the MIT Teaching Systems Lab, Thesis Supervisor May 25, 2018

Accepted by:

Katrina LaCurts, Chair, Master of Engineering Thesis Committee 


\title{
Design of a Teacher Education Model that Improves Teacher Educator Efficiency in Processing Teacher Candidate Data
}

\author{
By Kevin Ng \\ Submitted to the Department of Electrical Engineering and Computer Science \\ On May 25, 2018, in partial fulfilment of the \\ requirements for the degree of \\ Master of Engineering in Electrical Engineering and Computer Science
}

\begin{abstract}
Existing state of the art practice-based teacher education models either rely on heavy teacher educator time commitment to process teacher candidate performance stored in rich media like audio or video, or rely on teacher candidates to voluntarily share experiences with minimal teacher educator interaction with data. Using an iterative design process, I work with teacher educators to gauge interest in and build a new teacher education model that simplifies how teacher educators interact with rich media. The new model builds on Teacher Moments, an online simulator for preservice teachers, and takes advantage of state of the art speech recognition and data visualization technology to help teacher educators learn the contents of rich media generated by teacher candidates without dedicating the time to listen or watch media. In my investigation, I find that there is an interest in such a model and that the new model succeeds in empowering teacher educators with the ability to use teacher candidate data to inform instructional decisions and substantiate discussion point during group debrief sessions.
\end{abstract}

Thesis Supervisor: Justin Reich

Title: Executive Director, MIT Teaching Systems Lab 


\section{Acknowledgments}

This thesis would not have been possible without the help of many people.

First, I would like to thank my advisor, Justin Reich, for giving me this opportunity to work in the Teaching Systems Lab. Justin's guidance and support has taught me so much about education and research in the social sciences.

I would like to thank YJ Kim for being such a mom and helping me with all the research and writing parts of the thesis I had no idea how to do.

I would like to thank Kevin Robinson for all of your patience and the help you provided with your technical and product development expertise. Your optimism and eagerness to learn taught me so much about open source development.

I would like to thank Meredith Thompson for providing me with so much background knowledge about practice-based teacher education and all you work organizing playtests.

I would like to thank the anonymous teacher educators for taking the time to speak and work with me to make this thesis possible.

And big thank you to all of the talented folks at the Teaching Systems Lab for your warmth and support. It's been a pleasure working with everyone.

Last but not least, I would like to thank my family: Mom, Dad, Winnie and Eric. Thank you for believing in me and supporting me not only through this thesis but all throughout my undergraduate and graduate years at MIT. I can't believe it's finally over. We made it. 


\section{Contents}

1 Introduction

2 Background and Context $\quad 15$

2.1 Practice in Teacher Education . . . . . . . . . . . . . 15

2.1.1 Virtual Classrooms: TeachLivE and Mursion . . . . . . . . . . 15

2.1.2 Video Analyses: MyTeacherPartner-Preservice (MTPP) . . . . . . . 16

2.1.3 Clinical Simulations . . . . . . . . . . . . . 17

2.1 .4 Teacher Moments . . . . . . . . . . . . . . 18

2.2 Prior Work . . . . . . . . . . . . . . . . . . . . . 19

2.3 Context and Participants . . . . . . . . . . . . . . . 20

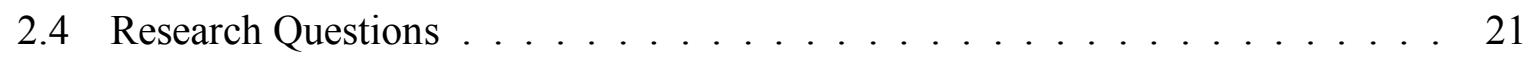

3 Experiment 1: Preliminary Work $\quad 25$

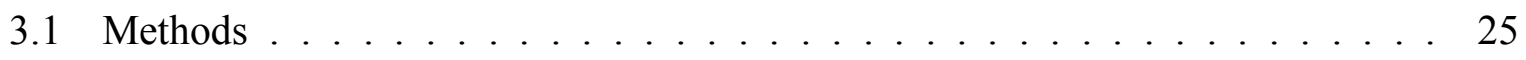

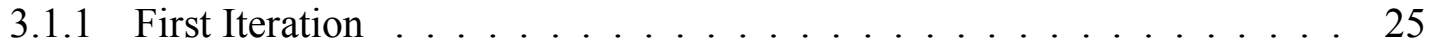

3.1 .2 Second Iteration . . . . . . . . . . . . . . 26

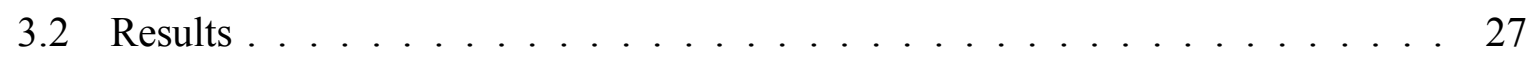

3.2 .1 User Profile: Jane . . . . . . . . . . . . . . . . . . . 27

3.2 .2 User Profile: John . . . . . . . . . . . . . . . . . . . . 28

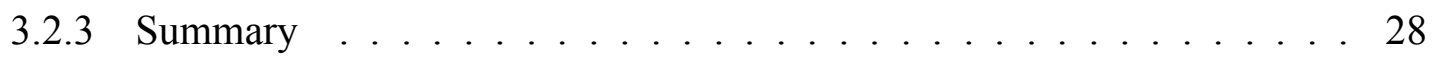

3.3 Discussion . . . . . . . . . . . . . . . . . . 29

4 Experiment 2 31

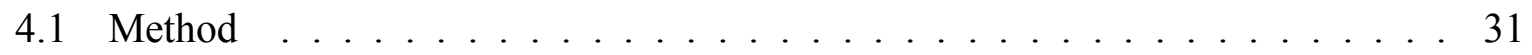

4.1.1 Designing the Teacher Educator Portal . . . . . . . . . . . 31

4.1 .2 Interview Protocol . . . . . . . . . . . . . 32

4.2.3 Data Analysis Protocol . . . . . . . . . . . . . 33

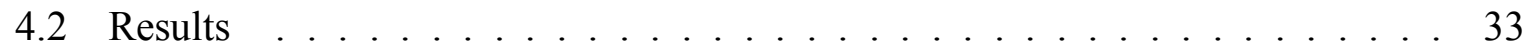


4.2 .1 New Model . . . . . . . . . . . . . . . . . . . . . . . . 33

4.2.1.1 Data Usage in Preparation . . . . . . . . . . . . . . 34

4.2.1.2 Data Usage in Discussion . . . . . . . . . . . . . 35

4.2.2 New Learning Experiences . . . . . . . . . . . . . . . . . . 35

4.2.2.1 Discovering New Learning Goals in Preparation . . . . . . 35

4.2.2.2 Pinpointing Topics of Interest in Simulations . . . . . . . . 37

4.2.2.3 Substantiating Teacher Candidate Claims in Discussion . . . 39

5 Discussion

5.1 The New Teacher Moments Model in Comparison to Existing Practice-Based Teacher Education Models . . . . . . . . . . . . . . . . . . . . . . . . 43

5.2 New Learning Experiences Facilitated by the New Teacher Moments Model . 44

6 Future Work $\quad 45$

6.1 Administrator Portal . . . . . . . . . . . . . . . . . . . . . 45

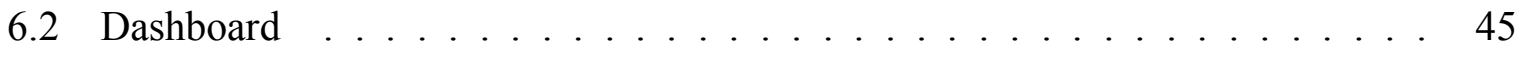

6.3 Uniform Data Storage . . . . . . . . . . . . . . . . 45

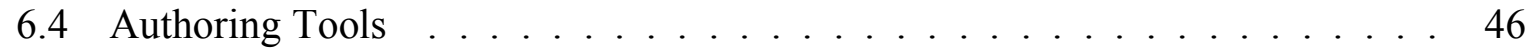

6.5 Toggling Visible Columns . . . . . . . . . . . . . . . 46

$\begin{array}{lll}\text { A } & \text { Teacher Moments Background - Jessica Turner } & 47\end{array}$ 


\section{List of Figures}

3-1 Teacher educator portal after first iteration $\ldots \ldots \ldots \ldots \ldots$

4-1 Final design for teacher educator portal . . . . . . . . . . . . . . . . 32 


\section{List of Excerpts}

4.1 "I think it's a fourth goal" . . . . . . . . . . . . . . . . 36

4.2 "I think it's a nice one to focus on" . . . . . . . . . . . . . 37

4.3 "Yeah? Let's find out" . . . . . . . . . . . . . . . . . . . . . 39 


\section{Chapter 1}

\section{Introduction}

Teacher education has been largely criticized for its ineffectiveness in preparing preservice teachers for success in the classroom. As a result of increasing demand for a shift in teacher education away from the traditional focus on theory and knowledge and towards practice-based curriculum, practice-based teacher education models have grown in popularity. Practice-based teacher education models focus on having teacher candidates develop and practice the skills needed for teachers to be successful in the classroom rather than simply learning about how to teach in lecture halls.

More and more, we find practice-based teacher education models that rely on new technology and data rich media, like video or audio, to aid teacher educators training teacher candidates. In these most of these models, teacher candidates are given the opportunity to teach or engage in some other interaction teachers experience in real classrooms or in simulation while being recorded or observed. In addition, a large majority of practice-based teacher education models involve a group debrief discussion to facilitate further learning, where candidates receive feedback from teacher educators and their peers. As a result, teacher educators can make connections between the teaching theory they learn in lecture and how it applies in practice. However, there are some drawbacks to these practice-based teacher education models. On one end of the spectrum, some models often require teacher educators to invest a substantial amount of time processing, watching or listening to media of teacher candidates practicing. For most teacher educators, investing so much time to provide feedback to each candidate is simply unsustainable. On the other end of the spectrum, to avoid overloading teacher educators, some models have teacher candidates review their own videos and share their experiences during the debrief discussion. In these, models, teacher educators have less control over what is discussed during the debrief discussion and are forced to rely on teacher candidates to keep conversation productive.

I argue that the drawbacks from both ends of the spectrum stem from the inability to quickly process the contents stored in rich media. Teacher educators have no way to quickly learn teacher candidates' experiences outside of watching or listening to entire practice sessions. 
There is no easy way to skim the through the information or to know exactly what parts to listen to. This forces teacher educators to make a decision: they can commit to investing the time necessary to work through all of the media, or they cannot look at it at all.

In this thesis, I present two experiments. First, using an iterative design process, I work with teacher educators to build user profiles and to gauge interest in a new practice-based teacher education model that enables efficient use of teacher candidate data. Then, I build the new practice-based teacher education model that enables teacher educators to essentially skim through the contents stored in audio and test it with teacher educators. I build upon an existing practice-based teacher education model, Teacher Moments, taking advantage of state of the art speech recognition and data visualization technology to simplify how teacher educators extract teacher candidate performance from audio. In the end, I demonstrate that a new practice-based teacher education model that facilitates skimming through teacher candidate simulation data gives teacher educators more control over debrief discussions and creates new, meaningful learning experiences for teacher candidates.

This thesis is structured as follows. Chapter 1 introduces the benefits and drawbacks to practice-based teacher education and motivates the problem that this thesis addresses. Chapter 2 provides more background knowledge of existing practice-based teacher education models, prior work on Teacher Moments and the teacher educators that I worked with. Chapter 2 also includes my research questions. Chapter 3 details the first experiment, the iterative design process in my preliminary work to gauge teacher educator interest in a new practice-based teacher education model. Chapter 4 describes the second, more substantial, experiment where I build the components for the new practice-based teacher education model, and the results of the experiment where teacher educators use the new model with a group of teacher candidates. Chapter 5 provides the concluding discussion of my research findings and Chapter 6 discusses future work that can be done to improve the new Teacher Moments model. 


\section{Chapter 2}

\section{Background and Context}

\subsection{Practice in Teacher Education}

"Teachers across the career span (induction, midcareer and veteran) speak of a divide between what they learned in their teacher preparation programs and the knowledge and skills they utilize in their classrooms" (Dotger, 2013). In contrast with clergymen and clinical psychologists, teacher candidates have less opportunities to practice the skills needed to be a teacher in comparison to their counterparts in the clergy and clinical psychology (Grossman, 2009). While teacher placements are used to gain experience, preservice teachers in these placements often depend on host teachers to decide how much control they have over a classroom and as a result, it is not uncommon for teacher candidates coming out of the same teacher training programs to have vastly different experiences (Hannah \& Abate, 1993). In an attempt to address this problem, four different research projects have led to new models of practice-based teacher education, leveraging technology and data rich media to aid teacher educators in training teacher candidates.

\subsubsection{Virtual Classrooms: TeachLivE and Mursion}

Lisa Dieker, a professor at the University of Central Florida tried to overcome the inconsistency in teacher placements by developing TeachLivE, an avatar-based learning platform where teacher candidates could practice teaching content and positive behavior strategies in a virtual classroom (Benedict, 2016). TeachLivE has since merged into Mursion, a virtual reality environment where professionals can practice and develop the interpersonal skills needed in education, healthcare and other fields (Schlueb, 2015). Teacher educators use Mursion to program virtual students to behave in certain ways in response to certain actions taken by the teacher candidate and give the students voice lines to interact with the teacher candidate. Teacher candidates engage with Mursion by teaching in front of a large monitor where up to five virtual student avatars sit in a classroom. A Kinect is used to track the candidate's actions in the classroom a headset is used to support the conversation between the teacher candidate and his students. With Mursion, teacher educators can control the content in a teacher candidate's 
experience to specifically target the candidate's learning needs. Teacher educators could set the instructional content, the number of students in the classroom and even the students' characteristics.

At over 65 universities and education programs across the United States, teacher educators use Mursion to give teacher candidates opportunities to practice teaching (Mursion). Teacher candidates have the chance to make mistakes and learn without the consequences of a real classroom. Immediately after simulations, Mursion shows analytics in the form of a graph on information like wait time between questions and answers, number of open ended questions asked or percentage of teacher talk versus student talk. However, feedback from teacher educators still plays a critical part of the Mursion-based learning experience. At UCF, Dieker called this the After-Action Review where teacher educators can support candidates in integrating what they learned in a classroom with what they experienced in the simulation. In some instances, teacher educators record the simulation and provide virtual feedback on the candidate's teaching. Other teacher educators may sit in the room with the teacher candidates to observe how they do and discuss with the candidate afterwards. Some even have other candidates in the room to observe, discuss and learn from each other as individual candidates do the simulation.

\subsubsection{Video Analysis: MyTeacherPartner-Preservice (MTPP)}

Adria Hoffman, a field placement coordinator in the Curry School of Education at the University of Virginia modified a professional development system to support teachers through video analysis and individualized coaching to create MyTeacherPartner-Preservice (Benedict, 2016). She uses MTPP in her school of education to periodically record teacher candidates as they teach so Hoffman and her team of two teaching assistants can provide high quality, rigorous and consistent feedback to teacher candidates throughout the program. They assess teacher candidates in three areas: emotional support, classroom organization and instructional support, using the Classroom Assessment Scoring System, a observational instrument created at the University of Virginia.

Prior to teaching, the candidate submits and receives feedback on a lesson plan. After they've been recorded teaching the lesson, a staff member watches the video and selects four or five instructional moments during the video for the candidate to focus on during analysis. The 
staff member gives a series of prompts that aim to direct the candidate to examine their teaching and the teacher-student interactions in the video. Afterwards, the candidate has a face-to-face meeting with the staff member. The meeting follows a protocol to unpack the contents in the video and to come up with an action plan for how the candidate can improve. This process is repeated six times over the course of the program to provide continued and consistent feedback on which teacher candidates can improve on.

\subsubsection{Clinical Simulations}

Ben Dotgers, a professor at Syracuse University's School of Education came up with an idea to have teacher candidates do clinical simulations, similar to the simulations that over $95 \%$ of medical institutions use to teach and assess medical students. Simulations involve trained actors who would consistently represent for example, a disgruntled parent, in order to simulate awkward or uncomfortable conversations with teacher candidates in the graduate school of education program. This would not replace traditional teacher placements but would offer rich learning experiences for teacher candidates to experience, practice, reflect and learn from experiences that resemble situations they would encounter as teachers (Dotgers, 2013). Each simulation involves a series of verbal triggers that are designed to draw conversation to certain topics and provoke cognitive dissonance. Cognitive dissonance is a state where an individual is forced to confront beliefs or attitudes that are inconsistent with their own, resulting in discomfort and the need to reevaluate one's own beliefs or attitudes in order to relieve the discomfort and return to state of equilibrium. Cognitive dissonance is commonly experienced among novice teachers and teacher education programs need to equip preservice teachers with the skills to make sense of their professional identity (Cook, 2009). Dotgers's simulations are designed to expose preservice teachers to specific situations where cognitive dissonance can occur to give preservice teachers an opportunity to practice recovering from disequilibrium. Through this shared experience, teacher educators could rely on teacher candidates to engage in meaningful discussions around professional values and the skills necessary to succeed as an educator.

Ben Dotgers offers two different types of reflection after his students complete a simulation, raw reflections and data-based reflections. First, immediately after the simulation, there is a raw reflection that captures all of the immediate visceral reactions teachers have. Dotgers has a set of generic open-ended questions he will ask followed by more simulation- 
specific questions relating to verbal triggers but his goal in the raw reflection is to provide an environment where a teacher can get out all of their thoughts about the simulation.

For the data-based reflections, Dotgers asks his students to review a video recording of themselves in the simulation and identify video clips that show their personal strengths and areas that needed improvement to share with their peers at a 2.5-hour group discussion. Dotgers makes an effort to only use video data that his students voluntarily bring to the debrief discussion. To start, he asks for a student to share a video clip. The student describes what occurs in the video clip and why the class is going to watch the clip. The video is played and the student is given the choice to have the last word or to solicit feedback from their peers, all of whom have experienced the same situation. Afterwards, students who picked clips handling the same trigger are invited to share which ends up giving the class a variety of approaches to handling the same trigger on which a broader discussion on improving teacher practices can take place. Dotgers serves solely as a facilitator to guide whatever discussion comes up from the video clips that are shared.

Dotgers argues that having the video data in the group discussion is valuable to help teachers figure out what happened in a simulation and how those actions may be used or improved on in a real situation. Too often, teachers do not have the time and technology to carefully examine their actions. By having the data, they don't have to rely on gut reactions and intuition, and as a group, they can come up with a thoughtful plan on how to handle similar situations in the future (Dotgers, 2013).

\subsubsection{Teacher Moments}

Teacher Moments is a teacher practice space designed at MIT's Teaching System Lab that presents teacher candidates with short classroom scenarios and gives them spaces to practice their responses to students in the moment. It gives teacher candidates a safe space to learn how to navigate difficult situations with students and/or their parents, focusing on skills related to motivating students, encouraging Next Generation Science Standards inquiry practice and addressing misconceptions (Teacher Moments). Teacher Moments is inspired by Ben Dotgers's work on clinical simulations but aims to remove the costs of having actors and physical space to conduct the simulations, using instead, a multimedia platform that uses video and audio recordings simulate the interactions. 
Similar to how Dotgers runs his clinical simulations, Teacher Moments provides teacher candidates first with a briefing explaining the context behind the situation they are expected to handle. Following the reflection guide in Dotgers's book "I Had No Idea", Teacher Moments has teacher candidates answer some pre-simulation reflection questions describing their expectations and post-simulation reflection questions that serve as the raw reflection that Dotgers conducts with his students. To replace the actors in the simulation, Teacher Moments relies on a series of videos that chronologically map out the lines of the actor and contain the verbal triggers Dotgers designed. Teacher candidates' responses are recorded as they speak to "the actor" or segment of the simulation through the series of videos. While the data-based reflections that Dotgers hosts with his students is conducted based on what the teacher candidates remember from the simulation, Teacher Moments does not give teacher candidates or teacher educators access to the text-based reflections or the audio-based conversations from the simulation for debrief discussions.

\subsection{Prior Work}

Since the creation of Teacher Moments, the Teaching Systems Lab has done more work on improving the teacher candidate experience during simulations. Simulations were first completely text-based. To improve the authenticity of the experience, researchers at TSL created parent teach simulations that used recorded video prompts rather than text (Owho-Ovuakporie, 2017; Thompson). The triggers that Dotgers designed for actors to use during clinical simulations are encoded within short video segments where an actor speaks with teacher candidates. The videos represent a linear simulated conversation where the parent talks, then the teacher candidate responds, then the parent talks again and so on. To make the conversation seem more realistic, the videos play automatically and immediately after they play, a static image of the actor remains on the screen and Teacher Moments instantly begins recording the teacher candidate's response. This design denies teacher candidates the time to plan out a response and forces them to react as they would in a real face-to-face conversation with a parent. In a study with undergraduate preservice educators enrolled in an Introduction to Education course at MIT, researchers at TSL found that this design allowed for these specific Teacher Moments scenarios to meet a set of criteria necessary for a simulation to be perceived as an authentic experience, to 
create cognitive dissonance within teacher candidates, and to give teacher candidates an opportunity to practice remaining calm in frustrating circumstances with parents while articulating their teaching philosophies.

The scenario used in this thesis is one developed in Owho-Ovuakporie's study and one inspired by the Jessica Turner Scenario in Ben Dotgers's book, “I Had No Idea”. The scenario forces teacher candidates to experience a teacher parent conference where they work with Jessica Turner, the angry parent of a student who is failing the teacher candidate's class. The simulation explains that the teacher candidate is a new teacher at the school and is using a novel approach to learning in the classroom that involves students actively seeking and constructing knowledge rather than simply sitting in lecture and regurgitating information on tests. Amber, the failing student, is famous in the suburban town as "the model" which causes her to miss class and assignments. She clearly dislikes the class, preferring traditional classroom models where she knows she can do well enough in. She maintains a healthy " $\mathrm{C}$ " in all of her other classes but is on the verge of failing the teacher candidate's class. Amber's mom, frustrated that her daughter is at risk of failing the class, demands a parent-teacher conference and this is where the scenario begins. A full transcript of this background can be found in Appendix A.

\subsection{Context and Participants}

The ABC Academy is a new Masters of Education program that launches in 2018 with the ambitious goal of reinventing American teacher preparation for the 21 st century with a competency-based blended curriculum. This preparation program offers a challenge-based curriculum where teacher candidates demonstrate a set of competencies by solving authentic problems of practices that teachers encounter in schools. Design fellows and faculty mentors at the ABC Academy work for a year before the inaugural year of the Masters of Education program to design the program's "challenge-based curriculum in a blended environment including online and face-to-face learning”. These design fellows and faculty mentors assess a variety of education tools and employ a selection of the tools in their curriculum. Prior to my thesis, the Jessica Turner scenario from Teacher Moments had already selected as a practice space that would be used in the curriculum. In my thesis, I work with two faculty mentors at the ABC Academy who will serve as faculty members in the upcoming school year in order to assess how access to teacher candidate data in Teacher Moments can inform teacher educators' 
decisions in a debrief discussion. I will refer to these two faculty mentors as John and Jane in this thesis.

\subsection{Research Questions}

Facilitated reflections play a crucial role in simulation-based learning to help learners make sense of their experience (Fanning, 2007). A common theme found throughout all practice-based teacher education models is that a facilitated debrief conversation is necessary to distill the learning goals of the activity and to discuss ways to improve on teacher candidates' performance. In practice-based teacher education models that use rich media to store teacher candidate performance, it is often difficult for teacher educators to extract personalized feedback for their students. In fact, most practice-based teacher education models that use rich media force teacher educators to invest either a significant amount of time to process the media or to invest no time at all. This is because there is no easy way to process information from rich media like audio or video efficiently.

Reviewing the practice-based teacher education models described from before, we can split the models into two groups: models that require a high investment of time for teacher educators to process teacher candidate data stored in rich media and models that require no time investment from teacher educators to process data stored in media. Both Mursion and MyTeacherPartner-Preservice represent models that are time intensive. Mursion requires teacher educators to either be physically present the entire time teacher candidates engage with the simulation or for teacher educators to record and watch candidates to provide feedback. MTPP requires teacher educators to watch videos of teacher candidates teaching a lesson and to find key instructional moments in each video for the candidates to reflect upon. Both models, while incredibly informative for teacher candidates, place an immense burden on teacher educators to spend time processing how their teacher candidates perform and creating personalized feedback. In contrast, Dotgers's Clinical Simulations and Teacher Moments both require no time investment from teacher educators to process data. Instead of having a small number of teacher educators process a lot data collected from a lot of teacher candidates, these two models offload the responsibility of processing data to the teacher candidates. Teacher educators using these two models don't ever see the data collected from teacher candidates engaging in the simulation, but 
rather, have teacher candidates self-report data during a debrief conversation. As a result, the teacher educators don't offer comprehensive, personalized feedback to each candidate and instead, rely on candidates to share their experiences and learn from discussing and comparing their approach with their peers.

While practice-based teacher education models that operate on either extreme of teacher educator time investment have shown success in improving teacher candidate learning. I hypothesize that there can be some middle ground in how much time needs to be dedicated to processing teacher candidate data stored in rich media. Research suggests that using data in instructional decisions can lead to improved student performance (Lewis, 2010). However, in these models of practice-based teacher education that rely on rich media, using teacher candidates' data means either having teacher candidates present their experiences without teacher educators using the data to inform their lesson plan, or having teacher educators fully process teacher candidates' performance stored in rich media, a task that does not scale.

Teacher Moments already collects data on candidate performance but this data never reaches the eyes of a teacher educator. In previous work on Teacher Moments, OwhoOvuakporie and his colleagues at TSL focused purely on improving the teacher candidate experience. This thesis focuses on improving the teacher educator experience in Teacher Moments. I explore how Teacher Moments could be expanded to give teacher educators access to teacher candidate data from completed simulations. Teacher Moments captures a vast amount of data on each participant that goes through the simulation. The system stores information on when buttons are pressed, what prompts are presented, scenario descriptions shown, user responses and more. Without access to teacher candidate data, teacher educators must infer what experiences teacher candidates encounter and rely on teacher candidates to voluntarily and accurately report anecdotes from memory.

In working with faculty mentors at the ABC Academy, I aim to learn what information teacher educators need in order to better understand and assess teacher candidates' competencies when engaging with a Teacher Moments simulation. Research suggests that using data in instructional decisions can lead to improved student performance (Lewis, 2010). When data analyses capture students' knowledge, educators can make informed decisions that positively affect student outcomes. 
In this thesis, I approach this investigation in two parts, one preliminary and one more substantial. In the Preliminary Work, I begin with a broad question of how to improve teacher educator experience in using Teacher Moments. I iterate with faculty mentors to build a teacher educator portal that gives teacher educators access to teacher candidate data in Teacher Moments and over the course of our iterative research, these research questions emerged:

1. What debrief experiences do teacher educators want in Teacher Moments?

2. What data do teacher educators need to create their ideal debrief experiences?

3. When exposed to new data possibilities, what do teacher educators want? In answering these questions, I hypothesize that there is a demand for a new practice-based teacher education model that enables teacher educators to quickly process rich media. In the more substantial Experiment 2, I examine how this new model affects teacher educator and teacher candidate interactions by answering the following additional research questions:

4. How does this new teacher education model align with existing practice-based teacher education models?

5. What new learning experiences are created using this new practice-based teacher education model? 


\section{Chapter 3}

\section{Experiment 1: Preliminary Work}

\subsection{Methods}

I approach this study from a design-based research perspective (van de Akker, 2013). In order to learn how to make Teacher Moments more useful and actionable as an education tool, I use iterative design cycles to learn the needs of the two faculty mentors. I collected this information in two iterations where I met with the faculty mentors and took notes on what they thought would be useful in improving Teacher Moments for teacher educators. From analyzing these notes, I infer what information about teacher candidate performance is useful for teacher educators and build a system to extract and present the data.

\subsubsection{First Iteration}

In the first iteration, my goal was to simply gauge interest in seeing teacher candidate data from Teacher Moments. I interviewed the faculty mentors from the ABC Academy for their thoughts on using Teacher Moments as a teacher education tool and how they would build a lesson plan around the Jessica Turner scenario. At this point, Teacher Moments did not provide teacher candidate data to teacher educators. I interviewed John and Jane separately to see how they each approached using Teacher Moments and to better learn what their individual needs as an educator were. Each teacher educator walked me through how they envisioned using the practice space in their classroom and explained what kind of information they might want from the Teacher Moments system and how that information would be useful to them as a teacher educator.

To get a more realistic perspective, I had John use Teacher Moments with a group of 4 in-service and 1 pre-service teachers at a playtest and lead a debrief discussion with the group as if they were students in his class. Jane could not host a playtest due to scheduling conflicts.

My interviews with John and Jane and observations from John's playtest suggested that the faculty mentors at the $\mathrm{ABC}$ Academy were open to the idea of pulling data on teacher 
candidate performance from Teacher Moments and using the data in planning and engaging with teacher candidates during debrief discussions.

As a result of this first iteration, I repurposed an internal TSL research tool that pulled all data collected in Teacher Moments to only display teacher candidates' unprocessed text and audio responses in a table. The table was completely static; teacher educators could scroll up and down to view the data and click play to listen to audio clips but otherwise, there were no other possible interactions. There are visible columns but they cannot be sorted. These features are artifacts of the original, internal TSL data analysis tool that extracted all stored data from Teacher Moments for researchers to analyze. An example of the information I decided to display can be seen in Figure 3-1.

\section{Events}

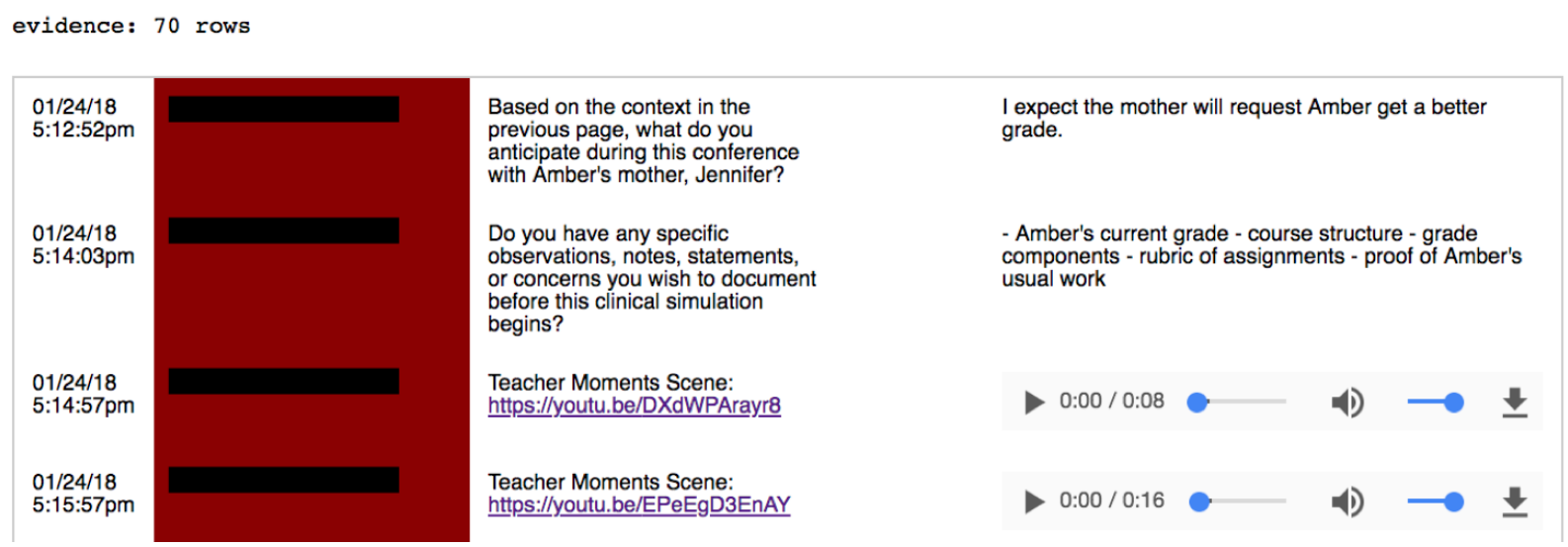

Figure 3-1: Teacher educator portal after first iteration

In this design, teacher educators can select which set of candidate data to look at via a dropdown menu at the top. They can view when a response was submitted, who submitted the response (redacted in this image), what prompt the candidate was answering and either a text-based or audio-based response from the candidate.

\subsubsection{Second Iteration}

In the second iteration, my goal was to better understand what data teacher educators needed in order to create their ideal debrief experience for teacher candidates. I met with John and Jane 
again, individually, and showed them the new teacher educator portal displaying teacher candidate data from John's playtest. We reviewed their previous approach to designing and leading a debrief discussion and I asked them if and how having access to teacher candidate data changed their approach. Additionally, faculty mentors proposed ways to improve the system.

\subsection{Results}

Overall, this experiment yielded a set of teacher educator user profiles that can be mapped to different preferred practice-based teacher education models used today. These two user profiles represent a small subset of different types of teacher educators. In these user profiles, for each type of teacher educator, I find answers to the following research questions:

1. What debrief experiences do teacher educators want in Teacher Moments?

2. What data do teacher educators need to create their ideal debrief experiences?

3. When exposed to new data possibilities, what do teacher educators want?

\subsubsection{User Profile: Jane}

Jane needs to be efficient. She sees Teacher Moments as a controlled and consistent alternative to live role-playing assignments that naturally lend towards more targeted discussions. From her previous experience as a teacher, she knows that time is of the essence and she needs to make good use of her time in the classroom to get her learning goals across to her students. She goes into class with a point she wants to make about the Jessica Turner scenario. She will run the class according to her agenda but is willing to tweak her agenda according to feedback from students about triggers they had trouble with. For her, though it is unlikely she will have the time to go through a lot of data, she thinks having overview information would be helpful in being able to easily get an idea of how the class is feeling.

When presented with the raw teacher candidate data, although Jane thought the concept of having all of the text and audio responses from her students sounded nice, she simply did not have the time to read through all of the responses and spend time clicking and listening to audio in order to process the information. She would consider skimming through the text responses but definitely would not listen to the audio without having some sort of transcript of the audio clips to signal what she would hear in the clip. If she were to read the text responses, she would want 
to be able to sort according to the question so she can easily compare students and quickly see how everyone responded to a certain question. In essence, even with access to the raw data from Teacher Moments, Julianna would not change her approach to designing a lesson plan or how she leads a debrief discussion.

\subsubsection{User Profile: John}

John wants to be responsive. He views Teacher Moments as a novel way to generate ideas about how to handle interactions. In using Teacher Moments in his classroom, he would use the builtin triggers to build a general structure for his debrief discussion but focus on using the triggers as a springboard into discussions around biases and professional values as teachers in response to what the teacher candidates say. He would ask his students what they want to talk about having all experienced the same scenario and be more than happy to deviate from his original plan. For him, data would be helpful in informing him of what topics teacher candidates are most interested in and in planning activities around those topics of interest.

When presented with the raw teacher candidate data, John was eager to be able to see how his students responded in the simulation. He wanted to be able to identify students and their responses and to reorganize the table by question to compare students' responses. John liked listening to the audio clips but would prefer having a transcript of the audio to easily learn the contents of all of the audio clips before listening to the clips for more verbal. Overall, John appreciated having the raw data but found it hard to use given the inability to reorganize the table and quickly process the information. He would likely use the information to guide the topics in his debrief discussion.

\subsubsection{Summary}

From the second round of interviews, I found that the raw data was not helpful to the teacher educators. As a research tool, a large table of data might be acceptable but for teacher educators, such a table took too much time to use. In hindsight, it is evident that John and Jane were looking for new forms of data derived from rich media that are not commonly found in practice-based teacher education models. They wanted something that they could skim so they could use teacher 
candidate data to inform their decisions without having to dedicate an immense amount of time to process rich media.

\subsection{Discussion}

Looking at previous practice-based teacher education models, Mursion and MyTeacherPartnerPreservice both use a lot of teacher candidate data in preparing for debrief discussions but are time intensive for teacher educators and require minimal teacher candidate initiative. They require a significant amount of time from teacher educators to watch or listen to each individual teacher candidate and to provide individualized feedback without requiring teacher candidates to take the initiative to share their thoughts. On the other end of the spectrum, Clinical Simulations and Teacher Moments in its original form require no time investment from teacher educators but require teacher candidates to voluntarily share information about their performance. From this experiment, I find that there is an interest from teacher educators in using a new practice-based teacher education model that utilizes data to inform teaching decisions, encourages teacher candidates to share their experience and does not require heavy time investment from teacher educators. Particularly, John's approach to developing an ideal debrief experience suggests a desire for a model that sits somewhere in the middle of the spectrum of balancing teacher candidate initiative and teacher educator time investment. John's user profile motivates Experiment 2 which aims to explore how a new model impacts teacher educator and teacher candidate interactions. Experiment 2 focuses on the following research questions:

4. How does this new teacher education model align with existing practice-based teacher education models?

5. What new learning experiences are created using this new practice-based teacher education model? 


\section{Chapter 4}

\section{Experiment 2}

\subsection{Method}

\subsubsection{Designing the Teacher Educator Portal}

Acting on feedback from Jane and John, I reimplemented the table to make it easier to read and enable users to sort the table according to students, questions and responses. The table uses a library called React Virtualized which specializes in displaying large tables of data. The table is virtualized, meaning that only the visible rows are rendered and displayed on the user interface, which helps the table efficiently display large amounts of data. This means teacher educators can scroll through and sort the data of many teacher candidates without the tool feeling slow or unresponsive. I also found an overwhelming desire for transcripts of the audio clips. Ultimately, this feature allows teacher educators to quickly skim the contents of audio clips without having to spend the time to listen to them. Here, I use IBM Watson's Speech to Text API to transcribe the audio files with a machine learning algorithm. Watson Speech to Text is quick and accurate in speech recognition and also creates opportunities for further work in recognizing key words and pauses, and in internationalizing Teacher Moments. The final design can be viewed in figure 4-1. 


\section{Events}

evidence: 59 rows

Timestamp Email

$04 / 05 / 18$

4:59:28pm
Prompt

Do you have any specific observations,

notes, statements, or concerns you wish

to document before this clinical simulation begins?

\section{Response}

I am concerned that Jennifer will not appreciate the way l've structured my class. I am also concerned that Amber will not be willing to re-engage with the classwork as she is comfortable with mid-level grades $(C)$ and does not mind regurgitation of material, which is in contrast to how I want students to deeply learn the material.

\section{$0: 00 / 0: 19$}

Transcript: "Turner I am very glad to have you come in today to talk about amber and I'm looking forward to how we can kind of work together and "

Figure 4-1: Final design for teacher educator portal

In this design, I keep the dropdown menu for teacher educators to switch between cohorts of teacher candidates. The table is now labelled and supports sorting on every column so teacher educators can choose to follow an individual teacher candidate through their entire simulation or simply compare how every candidate responds to a certain prompt. In the response column, as as audio data is retrieved from an online database and transcripts are transcribed, the table automatically updates with more information so teacher educators can get started reviewing reflection responses immediately.

\subsubsection{Interview Protocol}

I presented the teacher educator portal that I created and had John and Jane use the tools to prepare and lead the debrief discussion with teacher candidates. John and Jane were planning to use Teacher Moments with small groups of teacher candidates during the school year so we arranged to have a group of five teacher candidates participate in the playtest. Due to scheduling constraints, we had one playtest with the teacher candidates. As a result, John and Jane were 
interviewed together and lead the debrief discussion together. During the planning phase before the teacher candidates arrived, I showed the faculty mentors the teacher educator portal I built, had them design a debrief discussion plan and interviewed them for their thoughts. Following the planning phase, the faculty mentors immediately went into a recorded debrief discussion with the group of 5 teacher candidates who had agreed to complete the Jessica Turner Scenario and be part of this study. I took this as an opportunity to observe how the processed data manifested itself in the discussion. I use both what the faculty mentors say and what I observe to triangulate how this new model of practice-based teacher education affects teacher educator and teacher candidate interactions.

\subsubsection{Data Analysis Protocol}

With transcripts from the planning interview and debrief discussion, I annotated the transcript using a coding scheme that denoted how data was used. Specifically, during the planning phase, I noted when the teacher educators discussed whether or not to play teacher candidates' audio responses, when teacher educators read out the audio transcripts and when teacher educators actually listened to the audio clip. During the debrief discussion, I marked down when teacher candidates voluntarily spoke about their responses from memory, teacher educators asked to play teacher candidate audio responses, and when teacher educators actually played audio responses to support the conversation. From these annotations, I look for evidence of unique learning experiences that are supported by teacher educators having the ability to quickly and easily extract teacher candidate performance from rich media.

\subsection{Results}

A total of five teacher candidates participated in the experiment and attended the final debrief discussion. One teacher candidate failed to identify herself before starting the simulation so we could not retrieve her data. In total, 32 text-based reflection responses and 24 audio-based simulation responses were accessed and displayed to the teacher educators.

\subsubsection{New Model}


In this new Teacher Moments system, I built a teacher educator portal to facilitate the use of teacher candidate data. From the playtest, I find that the new Teacher Moments teacher education model differs from previous teacher education models in how teacher educators use data.

Teacher educators do not have to be present while teacher candidates engage with the simulation but still have a chance to review teacher candidate performance when designing the debrief discussion. Rather than having to listen to teacher candidates' complete audio recording during the simulation, teacher educators were able to skim through the transcripts of each segment of the simulation and only listen to clips that related to learning goals or where teacher candidates has interesting differences in approach. The actual structure of the debrief discussion remained the same in that teacher candidates voluntarily shared their experience with the simulation but having access to teacher candidate data gave teacher educators a better grasp of points of interest and the foresight to steer conversations towards those topics. As a result, this new Teacher Moments model falls in between models that require heavy teacher educator time commitment with little teacher candidate initiative like Mursion and MyTeacherPartner-Preservice and models that require minimal teacher educator time commitment and rely on teacher candidate initiative like Dotgers's Clinical Simulations and the Teacher Moments Owho-Ovuakporie worked on.

Diving deeper, we can look at how faculty mentors used the data in the playtest. From the recordings of the playtest, I noted 10 unique audio clips that the faculty mentors read and/or listened to, $42 \%$ of the audio data.

\subsubsection{Data Usage in Preparation}

During a 50-minute session where John and Jane designed a plan for their debrief conversation with their teacher candidates, I found that John and Jane relied heavily on the teacher candidate data collected from Teacher Moments to guide their planning process. They were visibly happy to see transcripts of the audio clips and discussed whether or not to play the audio clips on 3 separate occasions during the session. At one point, by reading the transcript of one of the candidate's responses, the teacher educators came up with a new learning goal. I discuss this interaction more in depth in the new learning experiences below. The teacher educator portal was projected on a screen so I could not count how much of the reflection responses and transcripts John and Jane read, but they read 6 different transcripts aloud and discussed what the candidates 
said at various points of the conversation. 3 of these discussions led John and Jane to actually listen to the audio clip. This simply was not possible before, and in the preliminary work without the audio transcripts, John and Jane were reluctant to listen to the audio.

\subsubsection{Data Usage in Debrief Discussion}

During the 60-minute debrief discussion with the teacher candidates, teacher candidates selfreported their responses during the simulation on 8 separate occasions. This form of data usage is used in Dotgers's clinical simulations and requires no additional work from teacher educators. However, given access to teacher candidates' data, the faculty mentors had an idea of how each candidate approached the simulation and were eager to offer to play the audio clips to support the claims each candidate made during the discussion. On 4 separate occasions, the teacher educators said things like "we're hoping that we could play some of what you said" and "let's find out" to indicate to the teacher candidates that they could play their audio files. Teacher candidates' audio clips were actually played twice during the discussion. I discuss this interaction more in the following section.

\subsubsection{New Learning Experiences}

This new model encourages teacher educators to process parts of media to understand teacher candidates' experiences. As a result, the model facilitates and creates new learning experiences that would otherwise be impossible using previous practice-based teacher education models.

\subsubsection{Discovering New Learning Goals in Preparation}

In the first excerpt, 11 minutes into the planning phase of the debrief session, faculty mentors John and Jane have already taken an interest in the contents of one of the audio clips. As I was explaining the teacher educator portal to them, Jane had already begun skimming the transcripts of the audio responses for possible discussion topics. After an exchange with John, Jane decides that "acknowledging strengths" is possibly a fourth goal, in addition to the 3 learning goals the two teacher educators had previously defined. Eventually, they decide to make this fourth goal actually a subset of one of the original goals.

Excerpt 4.1: "I think it's a fourth goal" 
Jane: I love the... Go up. Sorry, just to look at one. The one that says hesitation in all caps. That's so interesting as getting at one of our values thing. "I understand that Amber is definitely very ambitious, and has had a lot of success even now in her high school career with modelling. Hesitation. But I still think it's important. Amber had like, a very well rounded strong educational experience just like other students." That's a point where, seeing that, I'm like, "oh that looks like potentially acknowledging the family's values, Amber's strengths in this area and then tying back maybe their why to the teacher's why". So, that's one I would listen to.

John: I think the point about acknowledging strengths is something that's really important here. I'm not exactly sure which it fits with though, with the goals we chatted about.

Jane: I think it's a fourth goal.

John: Yeah.

Jane: Which is like, I think there's the active listening in challenging conversation I think is reframed more generically, like that's almost across any kind of challenging conversation to do active listening, empathy, and remain calm, but we do have a specific competency on engaging with families. And I think some of the things specific to how you interact with parents, you know, like ... grade level challenge, it was like not just calling when there is a problem but discussing the strengths too. So...

John: So if the first goal was actually instead of active listening, if it was like building relationship with a family, you might imagine like acknowledging the student's strengths would be a way to do that or a part of perhaps the first goal.

This conversation exemplifies the added benefits the new Teacher Moments model gives to teacher educators. Within moments of unveiling teacher candidate data, the teacher educators have already extrapolated new learning objectives from teacher candidates' experiences. 
Deprived of the data, the teacher educators had originally claimed they already had enough information and then, even when given the raw, untranscribed data, the teacher educators were reluctant to listen to teacher candidates' responses. Yet, given the audio transcripts, instantly they were ready to incorporate teacher candidates' experiences into the debrief discussion plan.

\subsubsection{Pinpointing Topics of Interest in Preparation}

In the next excerpt, John and Jane use the audio transcripts to pinpoint a topic that they want to discuss with the teacher candidates. Prior to the excerpt, they listen to 3 teacher candidates' audio responses to Mrs. Turner when she says: "Well I just need to know, is Amber going to pass your class?" With both the audio response and the transcripts in mind, John and Jane compare how the teacher candidates performed in comparison to each other. John commends two of the teacher candidates and Jane points out how the transcript fails to capture the energy and empathy Ashley uses to establish a connection with the parent. Ultimately, John and Jane both decide that the 3 different approaches they've seen from the 3 teacher candidates is worth discussing and plan on asking teacher candidates for permission to play their responses to add substance to the discussion.

Excerpt 4.2: "I think it's a nice on to focus on"

John: Yeah. And even so, I think like isn't the question ultimately, "Will she pass the class?" And I think you need to address both sides of it. If things change, here's what will happen. And if things don't change, be super explicit.

Jane: Right.

John: Which is what I think Ashley and Megan both communicated effectively.

Jane: But the tone feels... If we're talking about engaging the family, bringing them into the process, in many ways, Ashley's feels like a great, like an exemplar in that respect. Not the... The written part... really didn't capture it. But with her, "I'm so excited to have this conversation with you." 
John: Yeah.

Jane: "Because there's still time." That accomplished I think the energy, empathy connection goal and motivation to learn. Why would you keep showing up at all to a class if you've been told there's no hope? [chuckle] Yeah. But also still being clear that part of the point of this meeting I think in the framing to that was Amber's gonna fail if things don't change. I think is part of what they're being positioned as like... If that's the conversation you're having, better make sure that everybody leaves with an understanding of the reality that you're in. Now I feel like I'm just talking. What do you think about the different...

John: I think it's a nice one to focus on, to ask them if we could play the responses to that one potentially.

Jane: Yeah.

John: Because I think that it's one where they are acknowledging, especially Ashley, Megan, and actually Peter too. The work together piece. So there's the braid and to find a common ground.

Jane: Right.

John: And be collaborative in the situation, and also the clarity about the implications in combination.

This is an example of how teacher educators, given the ability to easily process and compare teacher candidates' responses in a simulation, are able to quickly pinpoint topics that should be discussed in the group debrief. This entire interaction began simply with John noticing one 
teacher candidate talking about whether or not Amber would pass the class and grew into a deep dive into how every teacher candidate responded to a single prompt. In most other practice-based models, pinpointing how all teacher candidates responded to a specific situation would require manually working through each candidates' entire film. Coupled with potential variations in how simulations run for each candidate, comparing teacher candidate performance in specific situations becomes an extremely difficult task for teacher educators. However, with the new Teacher Moments model, teacher candidate comparison is simple and time efficient.

\subsubsection{Substantiating Teacher Candidate Claims in Discussion}

In the final excerpt, John and Jane are actually leading the debrief discussion. As they go around the room having each teacher candidate discuss their response to Mrs. Turner questioning their teaching methods, John reaches Peter who claims he forgot what exactly he said. In response, Jane offers to play his response to the class. After listening to Peter's response, Peter reflects on how he could have done better and other teacher candidates offer their thoughts on his response.

\section{Excerpt 4.3: "Yeah? Let's find out"}

John: How about you, Peter?

Peter: I did not quite have the same reaction. My first reaction was, "Yeah, I am a first year teacher so I probably have a lot to improve on." I don't remember exactly how I responded to this one, actually.

Jane: Yeah? Let's find out.

Peter: Alright...

[laughter] 
Audio: Well, I wanna make sure that they can get the most out of their education whether or not they're in an AP or honors class. And that's pretty much my goal in doing the stuff that I could really help them learn.

Peter: Then as soon as I made that response, I was like, "Wow. That was a really dumb response." And so, that was my thought.

[chuckle]

John: How did it feel dumb?

Peter: The reason was, it sounded like... I don't know... That I assumed that they didn't know how to learn or something... That their daughter didn't know how to learn. I could just imagine a very negative response to what I just said.

Ashley: I think you didn't do a lot of bad things. You didn't say, "This is the way we teach now" or something condescending. Or... And you did focus on her. You were like, "I am doing this for the good of my students," which is an important thing.

Peter: That's true, yeah.

Megan: I just feel like acknowledging who you are and where you're at in your teaching career instead of trying to pretend you have more experience than you do is super important.

John: So that's a bright spot in Peter's response, right? Acknowledging where you're at. 
One of the main goals of having the debrief discussions in Teacher Moments, borrowed from Dotgers's Clinical Simulations, is for teacher candidates to be able to engage in meaningful conversation about how they responded in the simulation and exchange ideas on how to improve. In this case, when a teacher candidate is unable to recall how their response, practice-based teacher education models that rely on teacher candidates to share would be unable to recover. However, with the new Teacher Moments model, even though the teacher educators did not specifically process Peter's response, they were able to offer to play out his response and as a result, propelled the group discussion forward and make a point about how new teachers should not be afraid of acknowledging where they are in their career. 


\section{Chapter 5}

\section{Discussion}

Based on the analysis of the transcripts from the faculty mentor's planning and debrief discussion, I have found that the new Teacher Moments does represent a new model of practicebased teacher education and that this new model creates new learning experiences by empowering teacher educators with an increased understanding of how teacher candidates performed in simulations and the ability to use teacher candidate data at will during debrief discussions to substantiate points that teacher candidates make.

\subsection{The New Teacher Moments Model in Comparison to Existing Practice-Based Teacher Education Models}

What this new Teacher Moments model does for teacher educators is lower the activation energy required for utilizing rich media to inform learning decisions. In using the new Teacher Moments, faculty mentors, John and Jane, were able to easily process teacher candidate responses stored in rich media that they otherwise would have had to ignore due to lack of availability and time constraints. Consequently, they were able to effectively use teacher candidate data to inform learning decisions and maintain a debrief structure where teacher candidates take the initiative to share their experiences. The ability to operate in some middle ground, balancing teacher educator time investment and teacher candidate initiative, enables teacher educators to provide quality, debrief discussion catered to the unique experiences of all teacher candidates in the class without putting an unreasonable strain on teacher educators to process the information stored in rich media like audio and video. This, in part, is thanks to the unique structure of Teacher Moments, which takes the various triggers used in Dotgers's Clinical Simulations and divides them up among several segments. Having already split up the simulation into smaller chunks, teacher candidates' responses are also stored into small audio clips which can then be transcribed and displayed separately to facilitate sorting and other manipulations that aid teacher educators in gaining a better understanding of teacher candidates' experiences in simulations. 


\subsection{New Learning Experiences Facilitated by the New Teacher}

\section{Moments Model}

The purpose of all practice-based teacher education models is for teacher candidates to be able to candidly practice and for teacher educators to be able to lead a conversation afterwards that encapsulates the learning goals of the activity. From previous work, Teacher Moments is already capable of creating a realistic practice space for teacher candidates. From the playtest, the new Teacher Moments has shown that it takes an additional step in further enabling teacher educators to use data efficiently. With audio transcripts, teacher educators can quickly understand what teacher candidates experienced in the simulation and extract new learning goals that are specific to each cohort of teacher candidates. They can easily compare teacher candidates' responses and guide debrief discussions to expose the differences in their approach to promote further analysis and learning. Teacher educators no longer have to rely on teacher candidates to remember their responses and instead, can simply play their responses to spur debate. Ultimately, with this new model, teacher educators are given a choice to decide exactly which parts of the simulation to listen to to get more rich information in candidates' tone and pauses rather than being forced to process an entire simulation worth of responses. 


\section{Chapter 6}

\section{Future Work}

In this thesis, I really only develop a proof of concept of a new practice-based teacher education model that simplifies how teacher educators interact with data. This new Teacher Moments model still requires more work before it can be widely adopted and additional progress can be made in developing way to further condense information stored in rich media into easily consumable pieces for teacher educators.

\subsection{Administrator Portal}

There is currently no user interface for an administrator to register researchers with Teacher Moments to access data and to authorize researchers to get data associated with certain links. There is also no way to automatically update the internal list of participants who have authorized Teacher Moments to present their simulation data to a teacher educator or a researcher. All of these functions are possible from the perspective of a developer but in order to truly enable Teacher Moments to have self-serve data access, more work needs to be done to give relevant members at the Teaching Systems Lab the power to manage the data access system.

\subsection{Dashboard}

During the second iteration of the design process, Jane requested a dashboard with quick statistics in order to quickly understand how students felt without having to read through text responses and transcripts. Due to time limitations, I was unable to build this feature. Ultimately, this would require inserting quantitative questions in the pre and post reflection questionnaires that could be compiled into class statistics.

\subsection{Uniform Data Storage}

The collection of scenarios in Teacher Moments were built at different periods of time and sometimes by different developers. As a result, creating a general tool that could extract data 
from all of the scenarios is very difficult since the structure in which data is stored has evolved over time. As of now, the teacher educator portal is optimized to extract data from the Jessica Turner scenario and only works to varying degrees on other scenarios. Additionally, feedback from John and Jane ask for numbering the prompts in a scenario to make sorting by prompts more intuitive, and to add descriptions of videos to save teacher educators from having to click on the video links to know exactly what the prompt was.

\subsection{Authoring tools}

As Teacher Moments continues developing into a more viable tool in education settings, I believe there will be a growing desire from teacher educators to be able to develop their own scenarios. Although currently Teacher Moments does have an interface for creating scenarios, it has largely been untouched since it was first created and is currently incapable of creating scenarios like the Jessica Turner scenario. Ideally, new authoring tools could be developed that follow a uniform data storage protocol which would solve the problem of extracting data for analysis tools moving forward.

\subsection{Toggling visible columns}

The data that is presented currently in the teacher educator portal was entirely decided by my interpretation of what information teacher educators would find important. As described in the background, Teacher Moments collects much more than just the email of the participant, the prompt, the response and timestamp. Additional work can be done to notify teacher educators of what information they can get from Teacher Moments and enable teacher educators to toggle whether or not they want to see the data. This would also help with anonymizing the data table by hiding the emails column if teacher educators want to show textual responses to their class. 


\section{Appendix A}

\section{Teacher Moments Background - Jessica Turner}

Imagine you are a new teacher recently hired to work at Pleasantville High School, a small, suburban school within 1 hour's drive of a major metropolitan city.

You are beginning the second semester of your first year of teaching at Pleasantville HS. You've established an overall solid rapport with your students, as they recognize you as a teacher who is fair, consistent, knowledgeable, and has high expectations for student achievement.

One of your courses is a general course for 11th grade students. As a teacher, you believe that all students can learn. You structure your classes such that you support students as they grow intellectually while always keeping the academic pressure on, challenging them to continue advancing and to not become passive, stagnant individuals who just show up for class. This philosophy translates to a variety of independent in-class and out-of-class assignments. Never a fan of long lectures or worksheets, you structure most classes with a combination of minilectures, independent and group readings, and in-class projects or assignments. At times, students show frustration with the variety of learning activities. Some students appear to be more comfortable with you simply telling them what they will need to know, instead of challenging them to discover and construct knowledge themselves.

Amber Turner is a student in this class, but has made it clear that academics are not her focus. She is known throughout the small Pleasantville community as "the model," having appeared in several well-known clothing store and shoe commercials/photo shoots. Amber displays unmistakable arrogance and disdain for her peers and teachers.

It is clear to you that Amber sees high school as a waste or her time, as she is solely focused on her modeling career. The school's guidance counselor reports to you that she is maintaining a healthy " $\mathrm{C}$ " average in her other classes, In your class, though, her grades are in the low ' 60 's, resulting from a variety of absences and incomplete work. When she is in attendance and completes her work, her grades are sufficient — not the best completed assignments you've ever seen, but not "F" quality either. Amber's facial expressions, vocal sighs, and rolling eyes tell you she'd prefer a class where she didn't have to work, and where you just gave her the info and she regurgitated it back to you on a test. Your constructivist approach to 
your subject, though, causes Amber and her peers to actually have to put forth some effort.

You know that Amber is frustrated, and you're not surprised when you receive a somewhat curt handwritten note from her mother, requesting a conference with you. You inform Amber of a day/time that best suits your schedule, telling Amber that you're happy to meet her mother at the school. In response, Amber gives you a smirk and a distinct "now you're going to catch hell" look. 


\section{References}

Benedict, A., Holdheide, L., Brownwell, M., Marshall Foley, A. (Center on Great Teachers \& Leaders). (2016). Learning to Teach: Practice-Based Preparation in Techer Education http://ceedar.education.ufl.edu/wp-content/uploads/2016/07/Learning_To_Teach.pdf

Cook, J. S. (2009). "Coming Into My Own as a Teacher": Identity, Disequilibrium, and the First Year of Teaching. The New Educator, 5(4), 274-292. https://doi.org/10.1080/1547688X.2009.10399580

Dotger, B. H. (2013). "I had no idea": Clinical simulations for teacher development. Information Age Publishing.

Fanning, R., Gaba, D. (2007). The Role of Debriefing in Simulation-Based Learning. https://journals.lww.com/simulationinhealthcare/Fulltext/2007/00220/The_Role_of_Debr iefing_in_Simulation_Based.7.aspx

Grossman, P., Compton, C., Igra, D., Ronfeldt, M., Shanan, E., Williamson, P. (2009). Teaching Practice: A Cross-Professional Perspective. Teachers College Record, 111(9), 2055-2100.

Hannah, C. L., \& Abate, R. J. (1993). Survey on Faculty Use of Interactive Videodisc Technology in Teacher Education. Journal of Educational Technology Systems, 21(4), 321-332. https://doi.org/10.2190/PJT6-9RFU-0VU5-R69C

Lewis, D., Madison-Harris, R., Muoneke, A., Times, C. (2010). Using Data to Guide Instruction and Improve Student Learning. SEDL Letter, 21(2), Linking Research and Practice. http://www.sedl.org/pubs/sedl-letter/v22n02/using-data.html

Mursion. https://mursion.com/industries/education.html

Schlueb, M. (2015). Deal Moves Teaching Simulator Developed at UCF into Private Sector. UCFToday. https://today.ucf.edu/deal-moves-teaching-simulator-developed-at-ucf-intoprivate-sector/

Teacher Moments. https://tsl.mit.edu/projects/teacher-moments/

Thompson, M. Teacher Moments: An Online Platform. Unpublished manuscript.

Owho-Ovuakporie, K. (2017). Using "teacher moments" as an online practice space for parentteacher conference simulation in preservice teacher education. 
van den Akker, J., Gravemeijer, K., McKenny, S., Nieveen, N. (Eds.). (2006). Educational Design Research. London, UK: Routledge. Google Scholar 